\title{
In Situ Trans-Esterification of Residual Oils in Spent Bleaching Clays from Vegetable Oil Refineries
}

\author{
Prapassorn Phakahan ${ }^{a}$, Kornkanok Aryusuk ${ }^{a}$, Supathra Lilitchan ${ }^{b}$ and Kanit Krisnangkuraa, \\ ${ }^{a}$ School of Bioresources and Technology, King Mongkut's University of Technology Thonburi, Takham, \\ Bangkhuntien, Bangkok, 10150, Thailand \\ ${ }^{b}$ Department of Nutrition, Faculty of Public Health, Mahidol University, Rachathewi, Bangkok 10400, Thailand
}

\begin{abstract}
Spent bleaching clays (SBCs) from vegetable oil refineries are industrial wastes. The clays contain large amount of oils (20-25\%), which are good feedstock for biodiesels. Non-thermal in situ trans-methylation and transethylation of oils in the SBC from rice bran oil (RBO), crude palm oil (CPO) and palm kernel oil (PKO) are rapid and can be accomplished in minutes with an alkaline catalyst. Thus, the process may possibly be used for large scale preparation of ethyl biodiesel.
\end{abstract}

Keywords: Biodiesel, ethyl ester, methyl ester, palm kernel oil, palm oil, rice bran oil, spent bleaching clay.

\section{INTRODUCTION}

Biodiesel has been widely accepted for use in high speed diesel engine in many countries. Therefore, the growth in biodiesel production worldwide would lead to the development of novel processes that are more rapid, cost-effective and more efficient [1]. However, the major raw materials used for biodiesel production are vegetable oils and animal fats. Types of fats and oils used depend very much on the availability and they vary from country to country. Although palm oil can be produced domestically and it is the main raw material for the commercial biodiesels in Thailand, the supply is still far below the total demand for food and biodiesel. Spent bleaching clays (SBCs) from vegetable oil refineries, which have large amount of adsorbed oil would be a good source for biodiesel. Boey et al. [2] reported that SBC of crude palm oil (CPO) contained about 24 and $27 \%$ when extracted with petroleum ether and ethyl methyl ketone, respectively. An approximately the same percentage of extractable oil was reported by Huang and Chang [2] for SBC of soybean oil. The amount of oil was $21 \%$ when extracted with $n$-hexane and a higher percentage could be obtained when methanol, ethanol or polar compounds were used as the solvent but the extracted oil contained higher amount of pigments and polar and phosphorous compounds. Consequently, separation and purification of biodiesel was difficult. About 31 $36 \%$ residual cotton seed in SBC was reported by Ali et al. [3]. However, higher amount of residual oils (40\%) in SBC of soybean, palm and rapeseed oils were reported

*Address correspondence to this author at the School of Bioresources and Technology, King Mongkut's University of Technology Thonburi, Takham, Bangkhuntien, Bangkok, 10150, Thailand; Tel: +66 247 07759;

Fax:+66 245 23479; E-mail: kanit.kri@kmutt.ac.th by Lara Pizarro and Park [4] and lower amount (16.0\%) of residual palm kernel oil (PKO) was reported by Aladetuyi et al. [5].

The maximum yield of biodiesel (98.5 \%) from residual cotton seed oil on SBC was reported by Ali et al. [3]. The conditions were $\mathrm{NaOCH}_{3}(1.00 \%)$, methanol-oil $(6: 1)$ at $65{ }^{\circ} \mathrm{C}$ and stirring intensity $(650$ rpm) for 120 min. In situ trans-methylation was carried out by Boey et al. [6] with the aid of ultrasound with either petroleum ether or ethyl methylketone as a cosolvent. The mixture was sonicated at $55{ }^{\circ} \mathrm{C}$ for $2 \mathrm{~h}$. Optimal conditions were: $2.67 \mathrm{wt} \% \mathrm{KOH}$, methanol to oil mass ratio of $5.9: 1$ and $1: 1$ mass ratio of co-solvent. Although with the relatively high amount of catalyst, trans-methylation process gave approximately $60 \mathrm{wt} \%$ of methyl esters for the ethyl methyl ketoneas the cosolvent and $75 \mathrm{wt} \%$ of methyl esters for the petroleum ether as the co-solvent. Huang and Chang [2], on the other hand, prepared biodiesel from SBC by a two-step process. Conversion of the residual oil adsorbed in SBC into methyl esters was 84.5 to $90.1 \%$.

Studies on animal fats, Cunha Jr. et al. [7] reported that $96.25 \%$ conversion could be obtained with the alcohol to oil molar ratio $8: 1$ and $\mathrm{KOH} 0.88 \%$ at $70{ }^{\circ} \mathrm{C}$. Although higher yield was obtained at $70{ }^{\circ} \mathrm{C}$, they recommended lower temperature because lower soap formation and better phase separation. However, transesterification can proceed satisfactorily at room temperature [8, 9]. Bouaid et al. [8] showed that the best results for laboratory scale trans-ethylation reactions was $32{ }^{\circ} \mathrm{C}$ with $5: 1$ ethanol to oil molar ratio and $1.5 \%$ of $\mathrm{KOH}$ for high erucic acid brassica carinata $(91.3 \%)$, and high oleic acid sunflower oils (97.5\%) while the optimum condition for low erucic acid brassica carinata oil was $20{ }^{\circ} \mathrm{C}$ with $6: 1$ ethanol to oil 
molar ratio and $1.5 \%$ of $\mathrm{KOH}(98.3 \%$ yield $)$. A comparative study on the production of methyl and ethyl biodiesel from cotton seed oil, Fernandes et al. [10] found that the yields of methyl and ethyl biodiesels were $91.5 \%$ and $88.5 \%$, respectively.

Zhou [11] studied on the ethanolysis of sunflower oil at $23{ }^{\circ} \mathrm{C}$ using $1.4 \%$ mass of $\mathrm{KOH}$ (with respect to oil). Equilibrium was reached in 5 to $10 \mathrm{~min}$ for ethanol to oil molar ratios of 20,25 and 30 and at $60{ }^{\circ} \mathrm{C}$, equilibrium was reached in $2 \mathrm{~min}$. The yield of biodiesel from methanol, ethanol and butanol, for reaction at $23{ }^{\circ} \mathrm{C}$, were $99.4,98.6$ and $95.7 \%$, respectively.

Literature on in situ trans-esterification of SBCs was relatively rare and the biodiesel yields were low comparing to biodiesel from the extracted oils. Thus, the objective of this study is to investigate transesterification, especially the in situ trans-ethylation of SBC of different sources.

\section{MATERIALS AND METHODS}

SBCs of CPO, rice bran oil (RBO) and PKO were gifts of Surin refinery, Siam oil refinery and Lamsung Co. Ltd (Thailand). Solvents were analytical grade and mobile phases were HPLC grade from Lab Scan (Bangkok (Thailand).

\section{Extraction and Determination of Oil in SBCs}

The residual oil in SBC was determined by partial extraction method as described by Lilitchan et al. [12]. Two sample tubes contained 5 and $10 \mathrm{~g}$ of SBCs were mixed with $20 \mathrm{~mL}$ each of a solvent (ethyl acetate, dichloromethane and ethanol). The tubes were capped and vigorously shaken on a vortex mixer for $1 \mathrm{~min}$. The clays were allowed to settle. Two milliliters aliquots were taken from the clear liquids, evaporated to dryness under a stream of nitrogen. The dry residues were weighed and calculated for their equilibrium constant $(K)$, which in turn was used for calculation for total oil in the SBCs.

\section{Conventional Trans-Methylation}

Trans-methylation of the extracted oils from SBCs was carried out by dissolving $100 \mathrm{mg}$ of the extracted oil in $3 \mathrm{~mL}$ toluene and $1 \mathrm{~mL}$ of $1.0 \%$ methanolic $\mathrm{NaOH}$ and vigorously shaking on a vortex mixer for 1-2 min. One tenth $\mathrm{mL}$ of glacial acetic was then added to stop the reaction. The product was washed once with $2 \mathrm{~mL}$ of $2 \% \mathrm{Na}_{2} \mathrm{CO}_{3}$ and once with $2 \mathrm{~mL}$ of distilled water. The upper layer was transferred to another test tube, dried over anhydrous $\mathrm{Na}_{2} \mathrm{SO}_{4}$ and kept for HPLC and $\mathrm{GC}$ analysis.

\section{In Situ Trans-Ethylation}

Ten milliliters of $1.0 \%$ ethanolic $\mathrm{NaOH}$ was added to $5 \mathrm{~g}$ of SBC. The mixture was vigorously shaken on a vortex mixer for 1-2 min. The reaction was stopped by adding $0.5 \mathrm{~mL}$ glacial acetic acid. The clear solution was filtered through a 0.45 membrane filter, washed once with $2 \mathrm{~mL}$ of $2 \% \mathrm{Na}_{2} \mathrm{CO}_{3}$ and once with $2 \mathrm{~mL}$ of distilled water and dried over anhydrous $\mathrm{Na}_{2} \mathrm{SO}_{4}$. The trans-ethylated products were analyzed by HPLC and GC.

\section{In Situ Trans-Methylation}

In situ trans-methylation was carried out similar to the in situ trans-ethylation as described above. Because methanol is poor solvent for oils, toluene was added to help dissolving the oil. The amounts of toluene added were reported in the text.

\section{High-Performance Liquid Chromatography (HPLC)}

The HPLC system consisted of a Waters model 515 pump (Waters Associate, Milford, MA01757, USA.) equipped with a Rheodyne model 7125 six-port injector (Cotati, CA, USA), an evaporative light scattering detector (ELSD) model 55 from SEDEX (Sedere, Alfortville, France). A $100 \AA$ Phenogel column (300 x $7.8 \mathrm{~mm}$ i.d.) obtained from Phenomenex (Phenomenex, Inc., Torrance, CA) was used to check the purity of oils and reaction products. Sample and reference were prepared in toluene and analyzed on the Phenogel column with $0.15 \%(\mathrm{v} / \mathrm{v})$ acetic acid in toluene as the mobile phase at $1.0 \mathrm{ml} / \mathrm{min}$ flow rate[13]. The ELSD drift tube was set at $40^{\circ} \mathrm{C}$ and the $\mathrm{N}_{2}$ flow through the nebulizer was set at two bars. Peaks were identified by comparison with reference standards.

\section{Gas Chromatography}

GC analysis was carried out on a Shimadzu gas chromatograph model 2010 (Shimadzu Corp., Japan) equipped with an FID and a split-splitless injector. An Rtx-2330 (90\% biscyanopropyl, $10 \%$ cyanopropylphenyl polysiloxane) capillary column (30 $\mathrm{m} \times 0.25 \mathrm{~mm}$ i.d. $\times 0.25 \mu \mathrm{m}$ film thickness) was obtained from Restex International (Bellefonte, PA, USA). The chromatographic conditions were as follows: helium carrier gas flow, $2 \mathrm{ml} / \mathrm{min}$; nitrogen makeup gas flow, $30 \mathrm{ml} / \mathrm{min}$; detector/injector temperature, $250^{\circ} \mathrm{C}$; split ratio, about 50: 1 . 
Fatty acid identification was performed by its ECL value without reference standard according to Krisnangkura et al. [14] with the four column coefficients $(a=-7.169, b=-0.596, c=1007$ and $d,=$ 401.3) reported by Sansa-ard et al. [15].

\section{RESULTS}

\section{Extraction of Residual Oils in SBCs and Characteristic of the Oils}

All the oils in SBCs were very soluble in both ethyl acetate and dichloromethane. Twenty milliliters of the solvents could completely extract all the free triglyceride in $10 \mathrm{~g}$ of SBC. This is simply rationalized from the amount of oil extracted into the solvent. With $20 \mathrm{~mL}$ solvent, the amount of oil from $10 \mathrm{~g}$ of SBC was exactly twice that of the $5 \mathrm{~g}$ of the clay. Thus the adsorption constant $(\mathrm{K})$ cannot be determined for ethyl acetate and dichloromethane. On the other hand, ethanol was also a good solvent, but not as good as ethyl acetate or dichloromethane. The amount of oil extracted from $5 \mathrm{~g}$ of the SBC was more concentrate than oil extracted from $10 \mathrm{~g}$ of SBC. The $\mathrm{K}$ values were 0.318 for all types of SBCs. The oil contents of SBCs from RBO, CPO and PKO are summarized in Table 1. The extracted oils have different color, light brown, dark brown and pale yellow for RBO, CPO and PKO, respectively. The color reflexes pigment in the oils.

HPLC analysis on a $100 \AA$ Phenogel (Figure 1) shows a small peak eluted right after the main triglyceride (TG) for RBO and CPO, respectively. The retention time is the same as $\beta$-carotene and $\gamma$ oryzanol. HPLC chromatogram of PKO does not have this peak but there are many small peaks eluted at longer retention times. Composition and tentative identification of the oils by comparison of their retention times with the references are summarized in Table 2. RBO had very high pigment but low free fatty acid (FFA), while CPO had high pigment and FFA. PKO had no pigment but had other unidentified compounds.

The slightly different amount of oils trapped in the SBCs might be due to the different technologies used for oil filtration or due to the difference in viscosities of the oils. However, the difference in compositions, especially the impurities in different oils may be ascribed to the different process of refineries. RBO is chemically refined and FFA is removed by alkaline in the neutralization step. Accordingly, FFA in the subsequent step, including bleaching step, would be very low $(0.75 \%)$. On the other hand, palm oil is refined by physical refining process, where FFA was removed in the final deodorization step. Thus, large amount of FFA (10.9\%) was trapped in the SBC together with the oil. However, degumming and bleaching were separated into two steps. Thus, phospholipids in the clay were negleable. The very high amount of FFA in the SBC of CPO might reflect the FFA in the oil as well as the freshness of the fruit being processed. PKO was refined by physical process but degumming and bleaching were combined into one step. The SBC of

Table 1: Oils Extracted from $\mathrm{SBCs}(\mathrm{N}=3)$

\begin{tabular}{|c|c|c|c|}
\hline \multirow{2}{*}{ Solvents } & \multicolumn{2}{|c|}{ Refinery } \\
\cline { 2 - 4 } & RBO & CPO & PKO \\
\hline \hline Ethyl acetate & $25.2 \pm 0.70 \%$ & $23.1 \pm 0.4 \%$ & $21.4 \pm 0.8 \%$ \\
\hline Dichloromethane & $22.2 \pm 0.03 \%$ & $24.1 \pm 0.7 \%$ & $19.5 \pm 0.6 \%$ \\
\hline Ethanol $\left(\mathrm{K}^{1}\right)$ & 0.318 & 0.318 & 0.318 \\
\hline
\end{tabular}

${ }^{1} \mathrm{~K}$ is partition coefficient.

Table 2: Composition of RBO and CPO and PKO from SBCs Extracted with Dichloromethane

\begin{tabular}{|c|c|c|c|}
\hline \multirow{2}{*}{ Composition } & \multicolumn{3}{|c|}{ SBCs (\%) } \\
\cline { 2 - 4 } & RBO & CPO & PKO \\
\hline \hline TG & 92.75 & 79.1 & 88.3 \\
\hline Pigment & 6.5 & 7.1 & - \\
\hline DG & - & 2.5 & \\
\hline FFA & 0.75 & 10.9 & 5.0 \\
\hline Unknown & - & - & 6.7 \\
\hline
\end{tabular}



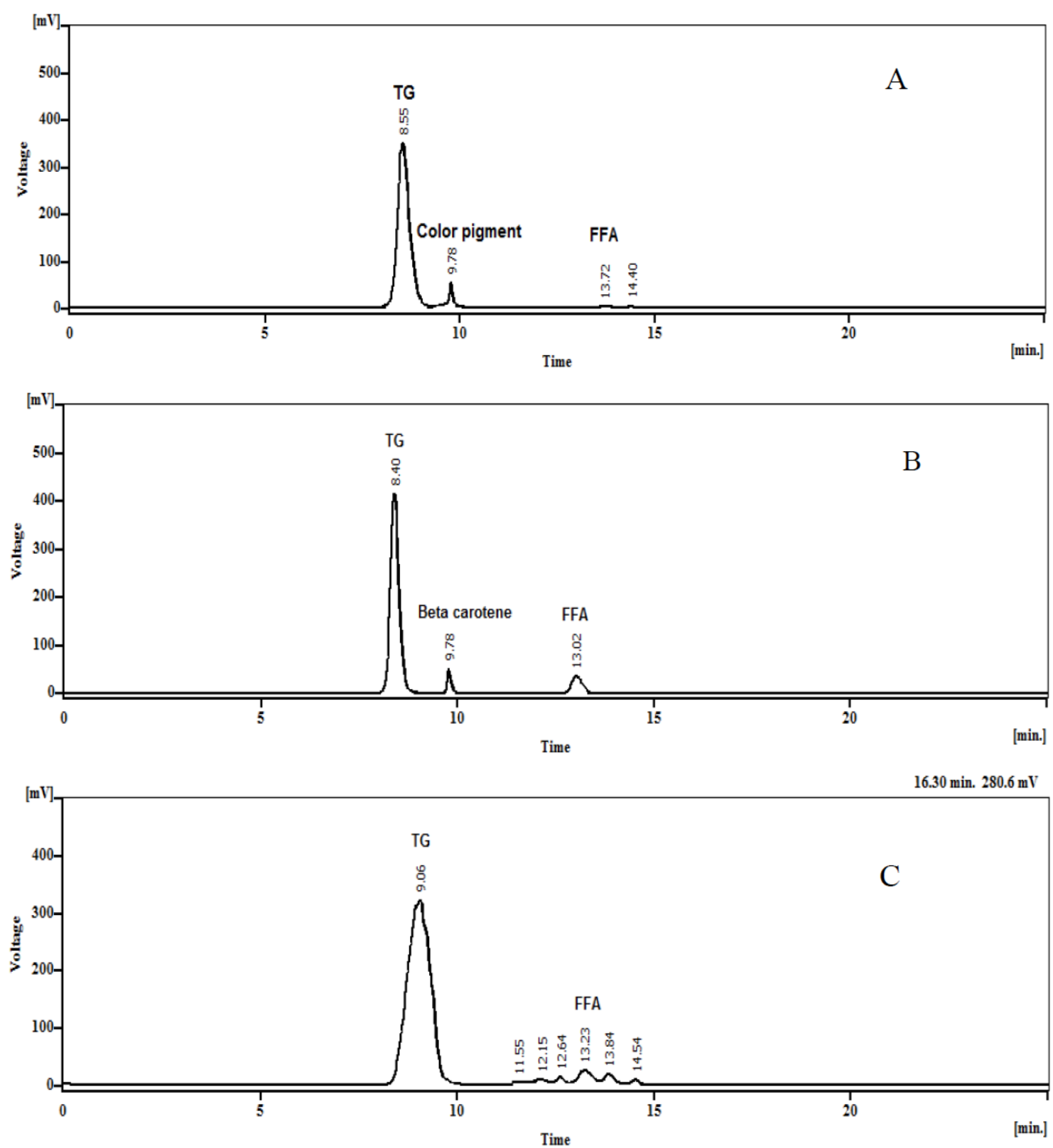

Figure 1: HPLC chromatogram of oils extracted from SBCs of RBO (A), CPO (B) and PKO (C) eluted from Phenogel $100 \AA$ column with toluene containing $0.15 \%(\mathrm{v} / \mathrm{v})$ acetic acid.

PKO contained large amount of both FFA (5.0\%) and other impurities.

Ethyl acetate could extract 21 to $25 \%$ of oil, which was slightly higher than dichloromethane (20 to $24 \%$ ) in all clays. However, ethyl acetate is highly flammable, thus scale up the oil extraction with this solvent must be very careful. On the other hand, dichloromethane is non-flammable and it is not allowed for use in food processing, thus it maybe suitable for industrial application. The oil content in the clays was quite high compared to oil bearing material used for biodiesel production. Rice bran, palm fruit and soybean contain $18-25 \%, 45-50 \%$ and $18-20 \%$ of oils, respectively [16].
Fatty acid compositions of SBCs of RBO, CPO and PKO are summarized in Table 3. The SBCs contained slightly higher saturated or higher melting fatty acids than the refined oils. It is speculated that the solid fats are possibly selectively retained on the SBCs or they are more viscous and consequently hard to pass through the filter press. However, the higher saturated fatty acid content would increase the cetane index of the biodiesel [17].

\section{Conventional Trans-Methylation}

Figure 2 shows trans-methylation of SBCs of RBO, $\mathrm{CPO}$ and PKO. Complete trans-methylation was 
Table 3: Fatty Acid Compositions of Oils Extracted from SBCs Compared to the Refined Oils

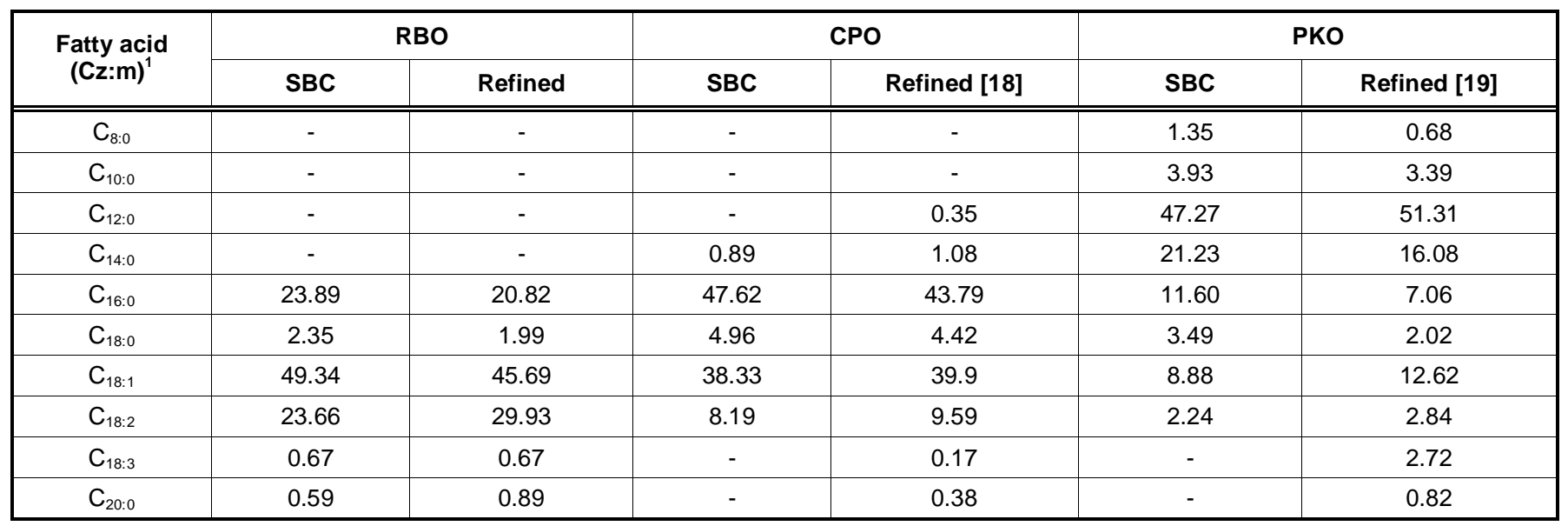

${ }^{1} \mathrm{z}=$ carbon numbers of fatty acid; $\mathrm{m}=$ number of double bonds.
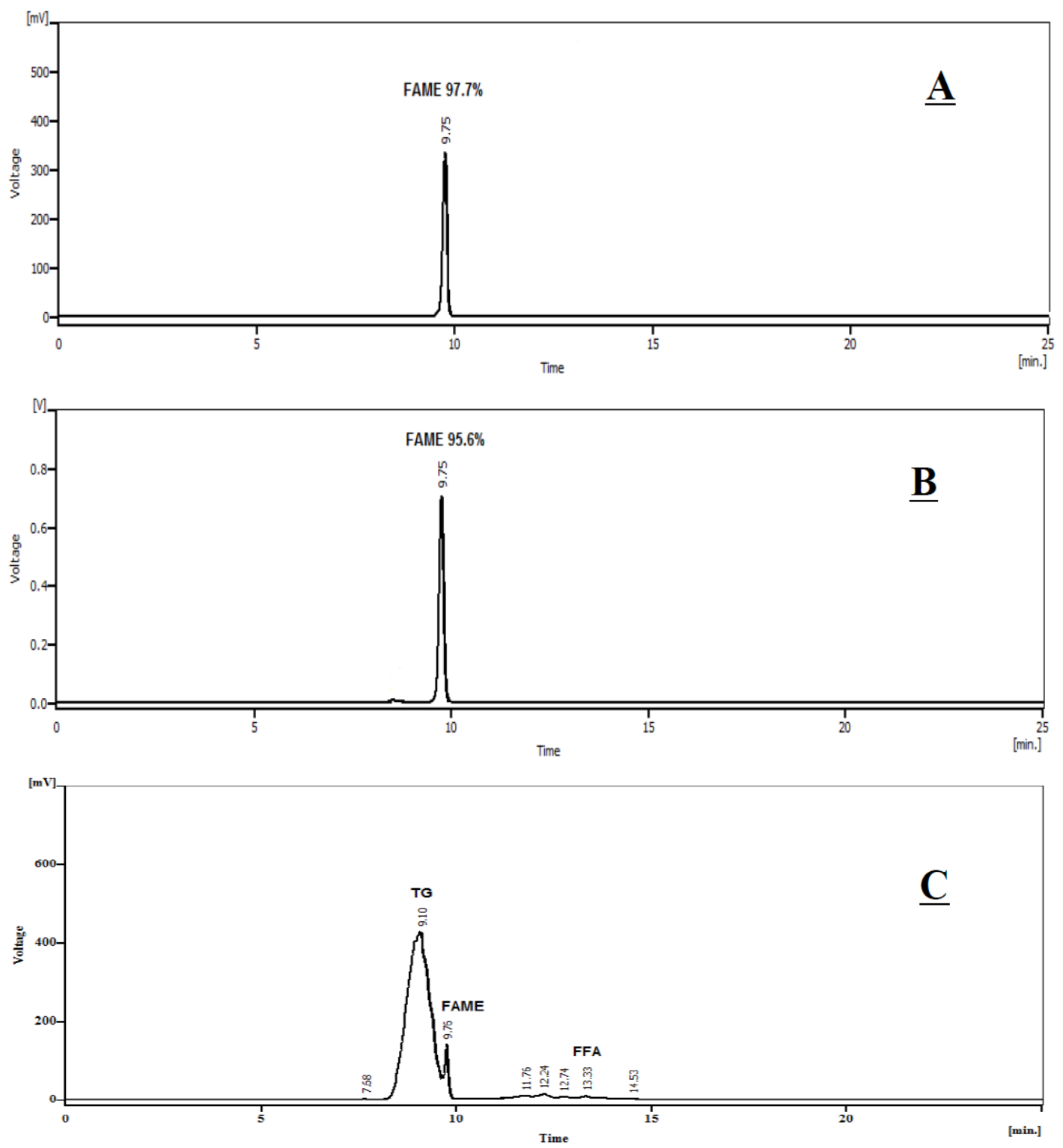

Figure 2: Trans-esterification products of oils extracted from SBCs of RBO (A), CPO (B) and PKO (C). See Figure 1 for chromatographic conditions. 


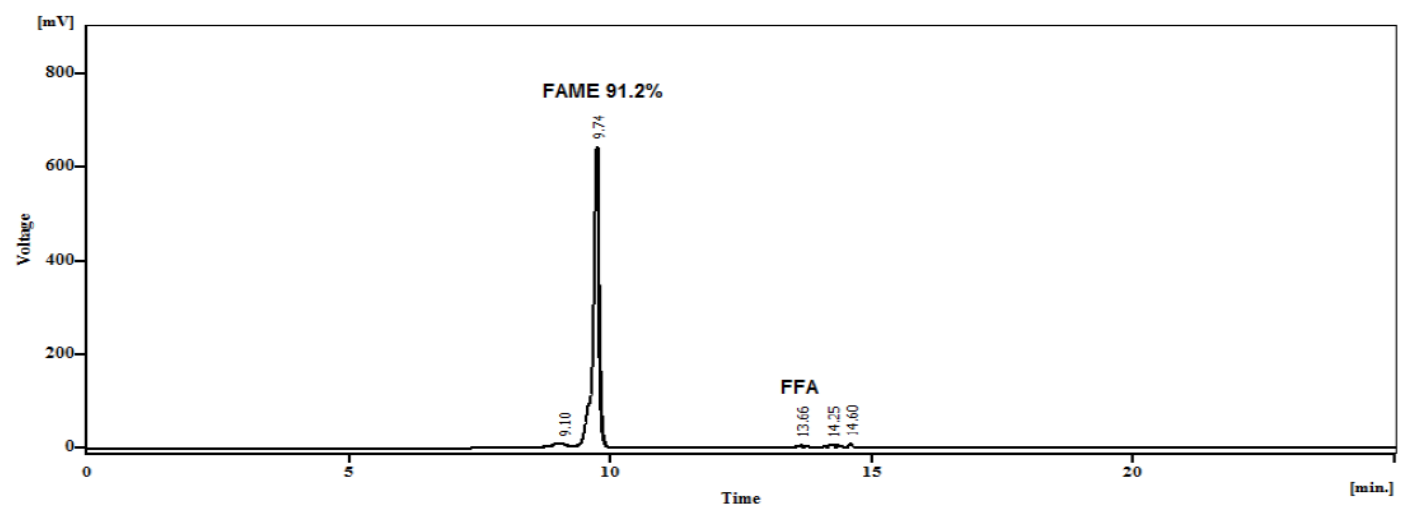

Figure 3: Trans-esterification products of oils extracted from SBC of CPO by conventional heat with $1 \% \mathrm{NaOH}$ for 30 min at 60 ${ }^{\circ} \mathrm{C}$. See Figure 1 for chromatographic conditions.

observed for RBO and $\mathrm{CPO}$, while PKO conversion was only $4 \%$ by conventional heat at $60{ }^{\circ} \mathrm{C}$ for $10 \mathrm{~min}$. The HPLC chromatogram of PKO (Figure 2C) shows that there are many impurities in the SBC of PKO. The $\mathrm{PKO}$ refining process is slightly different from $\mathrm{CPO}$ and RBO. The gum (mostly phospholipids) from the acid degumming step (PKO processing) was not removed while the bleaching clay was added to decolorize the oil. Therefore, all the gum was trapped in the SBC. In addition, Table 2 shows that there are about 5.0\% FFA and $6.7 \%$ unknown compounds in the SBC of PKO. Although the impurities in the SBC of PKO were not characterized, trans-methylation could be complete by adding more $\mathrm{NaOH}$ catalyst $(2.0 \%)$ or prolong the reaction to $30 \mathrm{~min}$ at $60{ }^{\circ} \mathrm{C}$ (Figure 3 ).

Also, the HPLC chromatogram in Figure 3 shows that all the impurities are disappeared except the FFA and the main biodiesel peak, suggesting that all the impurities might be the fatty acid base lipids and could be converted to biodiesel.

\section{In Situ Trans-Esterification}

In Situ trans-methylation of $5 \mathrm{~g}$ of SBC of CPO with $10 \mathrm{~mL}$ of $1.0 \%$ methanolic $\mathrm{NaOH}$ at room temperature was not complete. Only $13.2 \%$ conversion was observed at $1 \mathrm{~min}$. When $10 \mathrm{~mL}$ of toluene was added as a co-solvent, percent conversion was increase up to only $18 \%$. Therefore, the conditions were not suitable for in situ trans-methylation of SBC. Hence, $20 \mathrm{~mL}$ of $1 \%$ methanolic $\mathrm{NaOH}$ and $10 \mathrm{~mL}$ of toluene were used as the trans-methylation media for $5 \mathrm{~g}$ of SBC. Percent conversion was increased to $98.9 \%$ (Figure 4 ) in $1 \mathrm{~min}$. This can be simply explained as the increment in molar ratio of methanol to oil and higher available amount of $\mathrm{NaOH}$ for catalysis. In addition, the miscibility between methanol and oil in the presence of toluene as the cosolvent may also play an important role in accelerating the reaction. Without the co-solvent, surface contact between methanol and oil is limited to the extent of agitation. On the contrary, a homogeneous single phase is obtained for methanol and oil in the presence of toluene. Thus, surface contact between methanol and oil is infinity. Interaction between the two reactants is at maximum and limited by their actual concentrations. Therefore, trans-methylation was greatly enhanced and was complete in 1 min. However, the main disadvantage of co-solvent aided in transmethylation is the removal of co-solvent, which does not only increase the complexity but also increase an

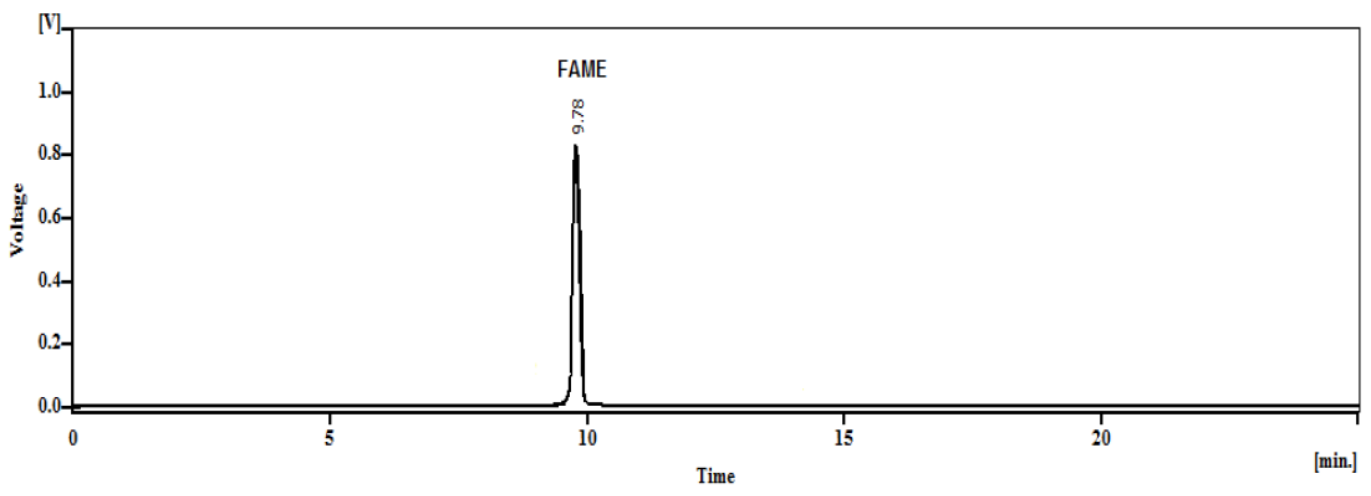

Figure 4: In situ trans-methylation of $\mathrm{SBC}$ of $5 \mathrm{~g}$ of $\mathrm{CPO}$ at room temperature with $20 \mathrm{~mL}$ of $1 \%$ methanolic $\mathrm{NaOH}+10 \mathrm{~mL}$ toluene for $1 \mathrm{~min}$. See Figure 1 for chromatographic conditions. 
additional cost to the process. When these conditions were applied to RBO and PKO, yields of biodiesel were $97.7 \%$ and $2 \%$, respectively. The peculiar result of PKO was possibly due to the presence of alkaline consuming impurities as mentioned above. The hypothesis was tested by increasing the $\mathrm{NaOH}$ to $2 \%$, conversion was increased to $97.0 \%$.

Ethanol has a greater power in dissolving the oil than methanol, while it is miscible with biodiesel at room temperature [20]. In situ trans-ethylation of $5 \mathrm{~g}$ SBC of CPO with $10 \mathrm{~mL}$ of $1.0 \%$ ethanolic $\mathrm{NaOH}$ was not complete in $1 \mathrm{~min}$. on a vortex mixer. About $81 \%$ of fatty acid ethyl ester (FAEE) was found together with $11 \%$ of $\mathrm{TG}$ and other intermediates in the reaction products. When the volume of ethanolic $\mathrm{NaOH}$ was increased to $20 \mathrm{~mL}$, trans-ethylation was $98.6 \%$ complete within $1 \mathrm{~min}$ with $0.7 \%$ of unconverted TG as shown in Table 4.

Table 4: Trans-Ethylation of $5 \mathrm{~g}$ SBC of RBO with Different Volume of $1 \%$ Ethanolic $\mathrm{NaOH}$.

\begin{tabular}{|c|c|c|}
\hline Lipid compound & $\mathbf{1 0} \mathbf{~} \mathbf{L}$ & $\mathbf{2 0 ~} \mathbf{~ L L}$ \\
\hline \hline TG & 11.7 & 0.7 \\
\hline FAEE & 81.1 & 98.6 \\
\hline FFA & 0.7 & 1.0 \\
\hline MG & 1.7 & - \\
\hline DG & 4.1 & - \\
\hline
\end{tabular}

Trans-ethylation of CPO showed similar trend as RBO. Trans-ethylation of CPO was about $99 \%$ complete in $1 \mathrm{~min}$ with $20 \mathrm{~mL}$ ethanolic $\mathrm{NaOH}$, but PKO gave only about $3 \%$ conversion. As it was pointed out earlier that PKO had larger amount of alkaline consuming impurities, higher amount of $\mathrm{NaOH}$ catalyst was required. It was found that $20 \mathrm{~mL}$ of $2 \%$ ethanolic
$\mathrm{NaOH}$ was suitable for $98 \%$ conversion of $\mathrm{PKO}$ in the SBC to biodiesel.

\section{Fuel Properties}

Fuel properties of the biodiesel products were estimated from their fatty acid compositions and are summarized in Table 5.

\section{DISCUSSION}

Generally, high FFA oils are not directly transesterified to biodiesel by alkaline catalysis. FFA does not only consume the alkaline hydroxide in the neutralization step, but the soap (a good emulsifier) also tends to complicate the biodiesel separation from alcohol. Therefore, FFA in the oil is reduced either by esterification with alcohol with an acid catalyst or washing with alkaline hydroxide. Lertsathapornsuk et al. [26] combined the alkaline washing and transesterification into one step to prepare biodiesel from high FFA waste frying palm oil. In this study, neutralization of FFA and trans-esterication of oil in SBC were combined. For $5 \mathrm{~g}$ of SBC of $24.1 \%$ of CPO (Table 1), there is $0.49 \mathrm{mmol}$ of FFA (Table 2 and MW 268 from Table 3 ), but $5 \mathrm{mmol}$ of $\mathrm{NaOH}$ was added to the reaction. Therefore, there was $0.9 \%$ of $\mathrm{NaOH}$ left as catalyst for trans-esterification. Therefore, prior to carry out trans-esterification, detailed analysis of contaminants in the SBC is essential. The rapid reaction of trans-ethylation might possibly due to the very high molar ratio of ethanol to oil (approximately 100). Usually, the alcohol to oil molar ratio is between 6 and 15 , but these ratio cannot be attained due to the solid clay, unless additional solvent is added for the extraction of the biodiesel entrapped in the clay.

Also, an interesting result was observed in Table 4 as well as several chromatograms (Figures 2-4). The

Table 5: Fuel (B100) Properties of Biodiesels from Various SBCs

\begin{tabular}{|c|c|c|c|c|}
\hline \multirow{2}{*}{ Fuel properties } & \multirow{2}{*}{ EN14214 } & \multicolumn{3}{|c|}{ SBC } \\
\hline & & RBO & CPO & PKO \\
\hline IV $\left(\mathrm{g} \mathrm{I}_{2} / 100 \mathrm{~g}\right)$ [21] & $120 \max$ & 85 & 47 & 11 \\
\hline $\mathrm{SN}[21]$ & - & 194 & 198 & 241 \\
\hline $\mathrm{HG}(\mathrm{MJ} / \mathrm{kg})$ [22] & - & 39.7 & 39.6 & 38.27 \\
\hline Viscosity $\left(\mathrm{mm}^{2} / \mathrm{s}\right), 40^{\circ} \mathrm{C}[23]$ & $3.5-5.0$ & 4.35 & 4.37 & 3.01 \\
\hline $\mathrm{CN}[17]$ & $51 \mathrm{~min}$ & 55 & 63 & 67 \\
\hline Viscosity $(\mathrm{cP}), 40^{\circ} \mathrm{C}$ & & 3.75 & 3.75 & 2.59 \\
\hline Density (g/cc) [24] & $0.860-0.900$ & 0.888 & 0.883 & 0.877 \\
\hline Surface tension $\left(\mathrm{mN} / \mathrm{m}^{2}\right)[25]$ & - & 29.66 & 29.16 & 28.06 \\
\hline
\end{tabular}


amounts of FFA in the reaction products are very much lower than the starting oils, especially the oil containing high FFA. The clay could remove sodium soap, but the mechanism of removal might not be established in this study. It might be a simple adsorption or the sodium soap form a semi-solid gel with alcohol and co precipitate with the clay.

SBC is an industrial waste from vegetable oil refinery. It contains very high amount of absorbed oil. The oil can be easily extracted with methylene chloride or ethyl acetate and trans-esterified to methyl or ethyl biodiesel. In situ trans-ethylation of the clay to ethyl biodiesel is very practical. In this study, a $99 \%$ conversion of the oil to ethyl biodiesel can be done within $1 \mathrm{~min}$. However, for commercial process, optimization must be done to lower the processing cost by lowering the amount of catalyst or alcohol (volume) to SBC (weight) ratio. Thus, reaction time would be longer and external heat must be applied to shorten the reaction time. Fatty acid composition of the absorbed oil was very similar to the crude oil, but the adsorbed oil contains higher amount of saturated fatty acids than the crude oil. This may be due to the higher melting point or pour point of the saturated fatty acid than the unsaturated fatty acid, allowing it to retain more on the clay. However, selective adsorption cannot be ruled out. Normally, biodiesel from saturated fatty acid has higher cetane index than unsaturated fatty acid of the same carbon atom [17]. Therefore, oil from SBC is better than the neat oil for preparation of biodiesel.

In situ trans-methylation of oil in the SBC is more difficult than trans-ethylation because of the lower solubility of the oil in methanol than in ethanol. This can be overcome by the addition of a co-solvent. With toluene as a co-solvent, reaction time can be shortened to that of trans-ethylation, but the major drawback is the removal or recovering of the co-solvent, which is an additional processing cost. Also, it must be kept in mind that different SBC contained different impurities. These impurities generally reacted or consumed catalyst. Thus additional amount of catalyst should be added to keep the strength of the catalyst in the required range. One percent of the catalyst would be sufficient to convert oil in SBC from alkaline refining process to biodiesel in one minute at room temperature.

\section{ACKNOWLEDGEMENT}

This work was supported by National Research University Project of Thailand's Office of the Higher Education Commission and Energy Policy and Planning Office, Thailand.

\section{REFERENCES}

[1] Guzatto R, Defferrari D, Reiznautt QB, Cadore ÍR, Samios D. Transesterification double step process modification for ethyl ester biodiesel production from vegetable and waste oils. Fuel 2012; 92: 197-203. http://dx.doi.org/10.1016/i.fuel.2011.08.010

[2] Huang Y-P, Chang JI. Biodiesel production from residual oils recovered from spent bleaching earth. Renew Energy 2010; 35: $269-74$

http://dx.doi.org/10.1016/j.renene.2009.07.014

[3] Ali Z, Waheed A, Iqbal H, Shah SF. Waste Bleaching Clay for Biodiesel through Base Catalyzed Transesterification of Residual Cotton Seed Oil. Asian J Chem 2016; 28: 725-32. http://dx.doi.org/10.14233/ajchem.2016

[4] Lara Pizarro AV, Park EY. Lipase-catalyzed production of biodiesel fuel from vegetable oils contained in waste activated bleaching earth. Process Biochem 2003; 38: 1077-82. http://dx.doi.org/10.1016/s0032-9592(02)00241-8

[5] Aladetuyi A, Olatunji GA, Ogunniyi DS, Odetoye TE. Production and characterization of biodiesel using palm kernel oil, fresh and recovered from spent bleaching earth. Biofuel Res J 2014; 4: 134 -8.

[6] Boey P-L, Ganesan S, Maniam G. Regeneration and Reutilization of Oil-Laden Spent Bleaching Clay via in Situ Transesterification and Calcination. J Am Oil Chem Soc 2011; 88: 1247-53.

http://dx.doi.org/10.1007/s11746-011-1781-4

[7] Cunha Jr A, Feddern V, De Prá MC, Higarashi MM, de Abreu $P G$, Coldebella A. Synthesis and characterization of ethylic biodiesel from animal fat wastes. Fuel 2013; 105: 228-34. http://dx.doi.org/10.1016/i.fuel.2012.06.020

[8] Bouaid A, Martinez M, Aracil J. A comparative study of the production of ethyl esters from vegetable oils as a biodiesel fuel optimization by factorial design. Chem Eng J 2007; 134: 93-9.

http://dx.doi.org/10.1016/j.cej.2007.03.077

[9] Kaewkool P, Kittiratanapiboon K, Aryusuk K, Krisnangkura K. Micro-reactor for transesterification of plant seed oils. Euro $\mathrm{J}$ Lipid Sci Technol 2009; 111: 474-80.

http://dx.doi.org/10.1002/ejlt.200800182

[10] Fernandes DM, Serqueira DS, Portela FM, Assunção RMN, Munoz RAA, Terrones MGH. Preparation and characterization of methylic and ethylic biodiesel from cottonseed oil and effect of tert-butylhydroquinone on its oxidative stability. Fuel 2012; 97: 658-61. http://dx.doi.org/10.1016/.fuel.2012.01.067

[11] Zhou W, Konar S, Boocock D. Ethyl esters from the singlephase base-catalyzed ethanolysis of vegetable oils. J Am Oil Chem Soc 2003; 80: 367-71. http://dx.doi.org/10.1007/s11746-003-0705-1

[12] Lilitchan S, Tangprawat C, Aryusuk K, Krisnangkura S, Chokmoh S, Krisnangkura K. Partial extraction method for the rapid analysis of total lipids and [gamma]-oryzanol contents in rice bran. Food Chem 2008; 106: 752-9. http://dx.doi.org/10.1016/j.foodchem.2007.06.052

[13] Kittirattanapiboon K, Krisnangkura K. Separation of acylglycerols, FAME and FFA in biodiesel by size exclusion chromatography. Eur J Lipid SciTechnol 2008; 110: 422 - 7. http://dx.doi.org/10.1002/ejlt.200700164

[14] Krisnangkura K, Tancharoon A, Konkao C, Jeyashoke N. An alternative method for the calculation of equivalent chain length or carbon number of fatty acid methyl esters in gas chromatography. J Chromatogr Sci 1997; 35: 329-32. http://dx.doi.org/10.1093/chromsci/35.7.329

[15] Sansa-ard C, Aryusuk K, Lilitchan S, Krisnangkura K. Free energy contribution to gas chromatographic separation of petroselinate and oleate esters. Chromatogr Res Inter 2011. http://dx.doi.org/10.4061/2011/252543 
[16] O'Brien RD. Fat and Oils: Formulating and Processing for Applications CRC Press, New York, 2004.

[17] Krisnangkura K. A Simple Method for estimation of cetane index of vegetable oil methyl ester. J Am Oil Chem Soc 1986; 63: 552-3.

http://dx.doi.org/10.1007/BF02645752

[18] Darnoko D, Cheryan M. Kinetics of palm oil transesterification in a batch reactor. J Am Oil Chem Soc 2000; 77: 1263-7.

[19] Kok S, Ong-Abdullah M, Ee GC, Namasivayam P. Comparison of nutrient composition in kernel of tenera and clonal materials of oil palm (Elaeis guineensis Jacq.). Food Chemistry 2011; 129: 1343-7. http://dx.doi.org/10.1016/j.foodchem.2011.05.023

[20] Kwanchareon $P$, Luengnaruemitchai $A$, Jai-In S. Solubility of a diesel-biodiesel-ethanol blend, its fuel properties, and its emission characteristics from diesel engine. Fuel 2007; 86: 1053-61. http://dx.doi.org/10.1016/j.fuel.2006.09.034

[21] Kalayasiri $P$, Jeyashoke N, Krisnangkura K. Survey of seed oils for use as diesel fuels. J Am Oil Chem Soc 1996; 73: 471-4.

http://dx.doi.org/10.1007\%2FBF02523921
[22] Krisnangkura K. Estimation of heat of combustion of triglycerides and fatty acid methyl esters. J Am Oil Chem Soc 1991; 68: 56-8.

[23] Phankosol S, Sudaprasert K, Lilitchan S, Aryusuk K, Krisnangkura K. An empirical equation for estimation of kinematic viscosity of fatty acid methyl esters and biodiesel. J Am Oil Chem Soc 2015; 92: 1051-61. http://dx.doi.org/10.1007/s11746-015-2667-7

[24] Phankosol S, Sudaprasert K, Lilitchan S, Aryusuk K, Krisnangkura K. Estimation of density of biodiesel. Energy Fuels 2014; 28: 4633-41. http://dx.doi.org/10.1021/ef501031z

[25] Phankosol S, Sudaprasert K, Lilitchan S, Aryusuk K, Krisnangkura K. Estimation of surface tension of fatty acid methyl ester and biodiesel at different temperatures. Fuel 2014; 126: 162-8. http://dx.doi.org/10.1016/j.fuel.2014.02.054

[26] Lertsathapornsuk V, Pairintra R, Aryusuk K, Krisnangkura K. Microwave assisted in continuous biodiesel production from waste frying palm oil and its performance in a $100 \mathrm{~kW}$ diesel generator. Fuel Process Technol 2008; 89: 1330-6. http://dx.doi.org/10.1016/j.fuproc.2008.05.024 